This PDF is a selection from an out-of-print volume from the National Bureau of Economic Research

Volume Title: Long-Range Economic Projection

Volume Author/Editor: Conference on Research in Income and Wealth

Volume Publisher: NBER

Volume ISBN: 0-691-04141-5

Volume URL: http://www.nber.org/books/unkn54-1

Publication Date: 1954

Chapter Title: Long-Term Projections of the Labor Force

Chapter Author: Harold Wool

Chapter URL: http://www.nber.org/chapters/c2930

Chapter pages in book: (p. 43 - 66) 


\title{
LONG-TERM PROJECTIONS OF THE LABOR FORGE
}

\author{
HAR OLD WOOL \\ OFFICE OF MANPOWER UTIIIZATION \\ DEPARTMENT OF DEFENSE
}

Projections of the labor force and labor input have provided logical steppingstones for the construction of forecasts of the nation's future productive potential. Thus the various post-World War II "full-employment" models and, more recently, the fiveyear projections of the Council of Economic Advisers used forecasts of the population and labor force as a point of departure and then allowed for frictional unemployment and hours of work to arrive at projections of man-hours of labor input. These were translated into projected or "goal" levels of the gross national product, by allowance for over-all productivity trends in the economy, i.e., gross national product per man-hour.

Despite the pivotal importance of the population and labor force trends in the appraisal of future levels of economic activity, economists have dealt only lightly with the assumptions and techniques underlying these projections. For example, until very recent years, they have tended to accept at face value projections of the population conveniently prepared for them by the demographers-in effect, treating population trends as exogenous to the economic climate being projected. Moreover, the labor force, as a percentage of the population, has been regarded as either independent of, or only mildly sensitive to, peacetime changes in the level or pattern of economic activity.

From the standpoint of fairly short-term projections, of five or ten years ahead, the assumption of relative stability in the labor input factors does not appear unreasonable, on a priori grounds:

1. From any given base year, the population of working age can normally be projected with a fair degree of accuracy, up to 15 years in the future, simply by a survival of existing population

Note: When this paper was prepared the author was with the Branch of Manpower Studies, Bureau of Labor Statistics. In developing the statistical materials he was assisted by Sophia Cooper and Stuart Garfinkle, of the Branch of Manpower Studies. The report was also reviewed in preliminary form by members of the staff of the Population Division, U.S. Bureau of the Census, and by Dr. Clarence D. Long, The Johns Hopkins University, who made many helpful suggestions. 


\section{THE LABOR FORCE}

cohorts and a realistic allowance for immigration. This is possible because of the general stability of mortality rates and the limited amount of immigration possible under current legislation.

2. Available data suggest that apart from wars or major cyclical movements, labor force propensities of particular population groups are fairly stable and slow-changing, since they are based in large part on deeply rooted social institutions and customs as well as on the prevailing geographic and occupational structure of employment. Once a proper base level is determined, consistent with the economic climate being forecast, extrapolation of past trends for specific population groups provides a reasonable point of departure. Moreover, an assumption of linearity-clearly unfeasible in the long run-may prove adequate for shorter-term periods.

3. Similarly, institutional and structural factors affecting "frictional" unemployment and hours of work can also be assumed to be fairly stable over the short run, in a given socio-economic environment.

However, a shift in time reference from "short-term" or "intermediate" to "long-term" introduces major qualitative changes in the problem of projecting levels of labor force and labor input. Trends in population, labor force, and hours of work can no longer be conveniently considered as autonomous forces, but are themselves influenced-in varying degree and at different time intervals-by basic structural changes in the economy and by many related socio-economic factors. For example, even within the broad framework of a peacetime "full-employment" economy, it is possible to construct sharply contrasting models, with different implications for labor force levels and trends. A consumption-orientated economy, with relatively low savings and investment rates, and stable or declining prices, would probably be accompanied by a lower labor force and lower average hours of work than an economy with high investment or defense expenditures, and predominantly inflationary tendencies.

The task of the analyst is rendered even more difficult by the fact that, although he may be able to judge the general effect of economic movements upon the separate labor input factors, he cannot-with available data and techniques-attempt to quantify these effects with any "scientific" precision. At best, he can present some rough approximations or a broad range within which the "true" level may be expected to fall. 
The specific problems of long-term population and labor force projection are discussed separately in the following sections.

\section{A. POPULATION}

Labor force projections, until the past few years, have been based, with few exceptions, upon the series of detailed population forecasts initiated in 1928 by P. K. Whelpton of the Scripps Foundation for Population Research and revised at periodic intervals until 1947. The Scripps projections published by the National Resources Planning Board in 1943 (and revised in 1947 in joint sponsorship with the Bureau of the Census) have been most frequently followed in projections of 1950 full-employment models during the past decade. ${ }^{1}$

The Whelpton method involved separate projections of three factors affecting future national population trends-mortality, fertility, and migration-by empirical analysis of past trends, by analysis of comparative, geographical statistics, and by evaluation of the influence of relevant social and economic trends. By applying the projected age-specific mortality rates to the last actual population, and "filling in" for births and for an assumed rate of migration, it is thus possible to project not only the size, but the composition, of the future population. The results of these projections have been presented in terms of a range, allowing for "high," "medium," and "low" assumptions as to fertility, mortality, and net immigration, and for various combinations of these assumptions.

\section{Fertility trends}

Of the three factors affecting long-term population trends, fertility is the most difficult to project and the most significant in terms of its impact upon future population growth in the United States. Prior to World War II, the existence of a long-term downtrend in the birth rate, both in the United States and in other industrialized nations, was accepted as a basic postulate in any analysis of future population and economic trends. The growing pattern of family limitation, reinforced by such factors as the movement from farm to city, was identified by demographers as the determining influence in this declining trend. Changing eco-

1 For bibliographical references, see Harold F. Dorn, "Pitfalls in Population Forecasts and Projections," Journal of the American Statistical Association, September 1950. 
nomic conditions, with their observed relation to cyclical fluctuations of marriages and births, were recognized as of primary importance in movements around the long-term trend. But these economic changes were interpreted as affecting only the timing of births in individual families-not the ultimate number of children per family. From the standpoint of long-run economic trends, prewar studies indicating a general inverse relation between fertility, on the one hand, and income levels and socio-economic status, on the other, appeared to strengthen the conclusion that a rising standard of living would be accompanied by a decline in the birth rate. The "medium" fertility projections in the various Scripps forecasts, therefore, allowed for a long-term downtrend in fertility from the rates prevailing at or near the base period.

The sharp divergence between the population forecasts and actual fertility experience during 1945-50 has already been subjected to intensive analysis and requires no detailed documentation here. ${ }^{2}$ In the earlier, 1943 projection, the "medium" estimate of births for 1945-50 had been set at 13.1 million. On the basis of information available by October 1945, this had been increased to 13.5 million. By the end of 1946 , and prior to the publication date of the 1947 forecast, the latter estimates were already obviously too low, and a revised "medium" estimate of 15 million births for the 1945-50 period was indicated. These forecasts contrast with actual births of 18 million during that five-year period. After attaining an all-time high of 3.8 million in 1947 (following the marriage "boom" in 1946) births continued at a near-record level of approximately 3.6 million in 1948-50, still 50 percent above the 1935-39 average of 2.4 million.

From the standpoint of long-term fertility trends, the maintenance of near-record births after 1947 is particularly significant since it occurred in the face of a sharp decline in marriages, from 2.3 million in 1946 to 1.6 million in 1949. To the extent that the initial postwar baby boom was due to a "catching-up" process following a period of depression and of wartime separations, the postwar baby boom could be regarded as a temporary phenomenon whose effects would wear off in the long run. However, after 1947, the over-all birth rate was sustained -not by initial births to newly wed couples, but by progres-

2 Dorn, op.cit., and Joseph S. Davis, The Postwar Population Upsurge in the United States (Stanford University, 1949). 


\section{THE LABOR FORCE}

sive increases in second-, third-, and even fourth-birth rates. Most demographers still tend to regard this phase as temporarya "borrowing" of extra births from the future as well as the past. However, there is reason to believe that we have experienced no merely temporary postwar spurt, and that some portion of this recent rise in fertility rates will persist in future years, if a goal of sustained full employment and rising living standards is to be approached in this country.

Two pieces of collateral evidence may be cited for this hypothesis. First, surveys conducted by the American Institute of Public Opinion in 1941 and 1945 showed a marked upward shift in the attitudes of young women as to the "ideal" number of children per family. This was attributed by Whelpton to "the psychology and economic conditions of the war." Secondly, the Indianapolis survey of factors affecting fertility, based on intensive case-history studies, has revealed that for those families which do practice effective family limitation, fertility rates tend to increase rather than decrease with rising income and socioeconomic status. These facts-still inconclusive and partial-do, however, suggest that from the standpoint of over-all fertility trends, the downward pressure of a continued trend away from very large families could be offset, at least in part, by the positive influence of a higher rate of marriage and by a reverse movement away from very small families, under conditions of sustained prosperity and general economic security.

\section{Mortality and immigration}

Although at present of lesser quantitative importance, the relation between economic trends and the other two major determinants of population growth-mortality and immigration-should also be taken into account. In both cases there is reason to believe that, other factors being equal, high levels of employment and progressive increases in living standards are positively associated with population growth. ${ }^{5}$

3 P. K. Whelpton, Forecasts of the Population of the United States, 194575 (Bureau of the Census, 1947).

4 Clyde V. Kiser and P. K. Whelpton, Social and Psychological Factors Affecting Fertility (Milbank Memorial Fund, 1949), p. 413.

${ }^{5}$ From the standpoint of shorter-term projections, mortality and immigration are the only factors affecting trends in the population of working age, i.e., 14 years and over. That variability in these factors is not negligible 
In recent years, the tremendous strides of medical science through the succession of "wonder drugs" have been cited as the major cause for the relatively sharp reduction in mortality rates. Perhaps of equal importance is the fact that with our relatively high living standards and improved medical care facilities, it has been possible to diffuse the benefits of these discoveries at a very rapid rate through the entire population.

As in the case of mortality, the association between the rate of immigration and domestic economic conditions is fairly evident. Prior to World War I, when immigration was uncontrolled, wide cyclical movements of immigration coincided closely with the general business cycle. Within the much narrower limits set by current immigration legislation, there is still room for sizable variation. For example, during the 1930's, immigration came to a virtual standstill, while in the period 1946-50, the net legal inflows into the United States averaged about 300,000 annually. The postwar immigration was due in part to strictly temporary circumstances (e.g., in the case of war brides and displaced persons). However, it also represented in part a response to favorable employment and other economic conditions here.

\section{Census "illustrative projections," 1950-60}

The mere recognition of some degree of correlation between the economic climate and the rate of population growth is not of direct value to the economic forecaster, unless he has some technique for identifying the relative importance of the economic factor. No such convenient tool exists at the present time. As a practical matter, the economist can select one from a range of available population projections, expressed in terms of projected trends of demographic factors, if he believes that it is reasonably consistent with the broad framework of his economic or other assumptions.

A current set of population projections which is suitable for this purpose was issued by the Bureau of the Census in August $1950 . .^{\circ}$ These projections, cautiously identified as "illustrative,"

is indicated by the fact that the "medium" 1943 Scripps projection of the population 14 years and over for 1950 was nearly 2 million below the actual, while the corresponding 1947 Scripps-Census projection proved to be 1 million too low.

${ }^{6}$ Jacob S. Siegel and Helen L. White, Illustrative Projections of the Population of the United States, 1950 to 1960 (Bureau of the Census, Series P-25, 43). 
use the postcensal population estimate of July 1, 1949 and the recent postwar experience in fertility, mortality, and immigration as a point of departure, and then allow for a relatively wide possible variation in trend from this level. Thus, the "medium" and "low" series assume a resumption (at different rates) in the long-term downtrend in fertility, but the "high" assumes a continuation of the high age-specific birth rates prevailing in 1948. A wide range is also allowed for in mortality trends and immigration-in the latter case, ranging from a low of "no net immigration" to a high of $350,000-400,000$ annually. As a result of these factors, the projected total population of the United States in 1960 ranges from a "low" of 161.7 million to a "medium" of 169.4 and a "high" of 180.3 million. About 13 million or over two-thirds of the difference between the low and the high projections is due to the difference in fertility assumptions, while slightly over 5.5 million is due to the range in the mortality and immigration assumptions.

In order to illustrate the implication of these alternative projections of total population for longer-range trends in the population of working age, the census projections of the population 14 years and over have been extended in this report to 1975 . These estimates were constructed by a cohort-survival method, i.e.: (1) using as a base the census "low," "medium," and "high" projections of total population for 1960, by age and sex; (2) estimating births in 1961 at about the same absolute level as projected, under each assumption, for 1960 (in order to derive the cohort aged 14 in 1975); (3) "surviving" the projected 1960 populations by an extension of the trends in the census "high," "medium," and "low" mortality rates to 1975; and (4) assuming continued net immigration in 1960-75 at the same level as projected by the Census Bureau between 1955 and 1960 under each of the assumptions.

As shown in Table 1, differences between the projected populations 14 years and over remain relatively small-although widening gradually-until 1965. By the latter year, the "high" projection is 9.8 million, or 7 percent above the "low" projection. This difference is almost entirely accounted for by the different assumptions as to immigration and mortality trends. However, in the following ten-year period, the cohorts born in the decade 1950-60 will be entering working age and as a result, the projections show a much wider divergence by 1975 , to 29.4 million, or 21 percent. 
TABLE 1

Projections of Population 14 Years and Over, 1950-75 UNDER "Hich," "Medrum," aNd "Low" Assumptionsa

(IN MILLIONS)

\begin{tabular}{lcccc}
\hline Year & High & Medium & Low & $\begin{array}{c}\text { Difference between } \\
\text { "High" and "Low" }\end{array}$ \\
\hline 1950 & 112.3 & 112.1 & 111.8 & 0.5 \\
1955 & 119.4 & 117.9 & 116.4 & 3.0 \\
1960 & 128.8 & 125.9 & 123.1 & 5.7 \\
1965 & 142.1 & 137.0 & 132.3 & 9.8 \\
1970 & 155.2 & 145.3 & 136.9 & 18.3 \\
1975 & 168.3 & 151.6 & 138.9 & 29.4 \\
\hline
\end{tabular}

a Projections for 1965-75 prepared by the Bureau of Labor Statistics by extension of projections for 1950-60 given in Illustrative Projections of the Population of the United States, 1950-1960 (Bureau of the Census, Series P-25, 43).

The sources of the differences in the projected populations are more clearly identifiable in Table 2, which compares the three projections for 1975 , by age and sex groups. Of the total difference between high and low projections of 29.4 million, 15 million is in the age group 14-24 years and is due very largely to the wide spread between the "high" and "low" birth-rate assumptions.

In view of the critical importance of the birth-rate trend in the next 10 years, as a determinant of the size of the population of working age a generation hence, it is necessary to evaluate the effect of relatively short-run social and economic forces upon fertility during the coming decade. It is noteworthy that after the preparation of the census projections in early 1950, the actual trend of births continued at a near-record annual rate of about 3.6 million during calendar year 1950 and then rose to a new high of 3.8 million in 1951. This rise can be traced to the direct and indirect effects of the Korean outbreak: the reactivation of Selective Service inductions, the increased tempo of economic activity, and the general heightening of international tension and uncertainties. These same factors are likely to exert continued upward pressure upon the birth rate during the next few years and perhaps for a decade or more. In view of these factors, the "low" projection, which assumes a rapid decline in births, to about 2.3 million in the second half of the decade, must be rejected as unrealistic-except under the explicit assumption of a sharp and sustained decline in economic activity. If a high level 


\section{TABLE 2}

Projected 1975 Population 14 Years and Over, by Age, UNDER "High," “Medium," aNd "Low” Assumptionsa

(IN MILLIONS)

\begin{tabular}{crrrr}
\hline Age & High & Medium & Low & $\begin{array}{c}\text { Difference between } \\
\text { "High" and "Low" }\end{array}$ \\
\hline 14 years & & & & \\
and over & 168.3 & 151.6 & 138.9 & 29.4 \\
$14-19$ & 22.9 & 16.7 & 13.1 & 9.8 \\
$20-24$ & 19.0 & 15.9 & 13.5 & 5.5 \\
$25-29$ & 18.1 & 17.7 & 17.1 & 1.0 \\
$30-34$ & 14.6 & 14.2 & 13.7 & 0.9 \\
$35-39$ & 12.1 & 11.6 & 11.0 & 1.1 \\
$40-44$ & 11.4 & 10.9 & 10.2 & 1.2 \\
$45-49$ & 12.3 & 11.7 & 11.0 & 1.3 \\
$50-54$ & 12.4 & 11.8 & 11.1 & 1.3 \\
$55-59$ & 11.2 & 10.5 & 9.9 & 1.3 \\
$60-64$ & 10.0 & 9.3 & 8.7 & 1.3 \\
$65-69$ & 8.2 & 7.6 & 7.1 & 1.1 \\
$70-74$ & 6.4 & 5.8 & 5.4 & 1.0 \\
75 years & & & & \\
and over & 9.4 & 8.0 & 7.2 & 2.2 \\
\hline
\end{tabular}

Detail does not necessarily add to totals because of rounding.

a Estimated by the Bureau of Labor Statistics from data in Illustrative Projections of the Population of the United States, 1950-1960 (Bureau of the Census, Series P-25, 43).

of defense spending and "full" or "near-full" employment continues during the greater part of the decade (without the actual outbreak of major hostilities), the "high" series, providing for an average of about 3.8 million births annually, may prove to have been the most probable. Somewhat more conservatively, we can assume that the population of working age in 1975 is likely to lie somewhere between the "medium" and "high" series, i.e., between 152 and 168 million.

\section{B. LABOR FORCE}

The level of the labor force and variations in its size are to a significant extent functions of the concepts and enumeration techniques used in labor force measurement. Prior to 1940, data on the size and composition of the United States working population were available only from the decennial censuses of population. In these censuses, statistics on the "gainfully occupied" population (or "gainful workers") were derived as a by-product of data on occupational attachment of persons of working age. 


\section{THE LABOR FORCE}

With increasing concern and interest in employment problems during the 1930 's, this approach proved to be inadequate and a "labor force" concept was adopted in the 1940 census. At about the same time, a monthly sample survey of the labor force was initiated which is currently conducted by the Census Bureau and published as the "Monthly Report on the Labor Force" (MRLF).

The current labor force concept differs from other approaches to labor force measurement in two major respects: (1) A person's relation to the labor market is determined primarily by his activity in a given week (i.e., working or looking for work), with supplemental provision for inclusion as employed of persons who have a job attachment, but who are not actually working for certain temporary causes, and for inclusion as unemployed of some "inactive" workers, if their failure to look for work is due to certain specified causes, such as indefinite layoff or short-term illness. (2) Labor force attachment, as thus defined, takes priority over other types of activity or status, such as student, housewife, or retirement. Thus a student, enrolled full-time in school, would be included as in the labor force if employed one hour or more during a given week for pay or profit, or for 15 hours or more as an unpaid family worker.

The above definitions have proved generally effective as a sensitive barometer of month-to-month and year-to-year changes in employment and unemployment and of the changing composition of the working population. The MRLF was an indispensable tool for measuring and evaluating the great wartime expansion of the labor force and the transition to a postwar high-employment economy. However, the use of the activity concept and the systematic inclusion within the labor force of "fringe" groups, such as students and housewives, when actually employed or seeking work, has resulted in a high degree of seasonality in the labor force totals (with a typical range of nearly 4 million from "high" to "low") and has tended to make the series relatively sensitive to cyclical changes in the level of labor demand. This volatility means that special care must be taken in selection of base levels, and in evaluation of past data for purposes of longterm projection.

In addition to the influence of seasonal and cyclical factors, experience with the labor force survey during the past decade has revealed that the labor force estimates are highly sensitive to even minor changes in enumeration procedures. Thus, the 
addition of a "probing" question on employment status in the MRLF survey in July 1945 and subsequent months resulted in an upward revision of 1.5 to 2 million in the labor force estimates, due largely to more complete enumeration of marginal workers, such as women and youths. The contrast between the preliminary sample results of the 1950 decennial census recently published and the comparable MRLF estimate for April 1950 is even more striking. The employment status questions in the 1950 census were almost identical to those in the monthly sample survey; yet the estimated total labor force in the decennial census of about 59.9 million (including armed forces overseas) was 3.5 million lower than the comparable MRLF estimate. This difference was attributed by the Census Bureau mainly to a difference in the levels of experience of the field staff. ${ }^{7}$

Comparison of the preliminary census results with the MRLF in Table 3 indicates that the greatest differences for 1950 occur among "marginal" groups, including women and teen-age boys, while much smaller differences are shown for adult men aged 25 years and over. In terms of trends, it will be noted that the general direction of the changes between 1940 and 1950 is similar for most of the age-sex groups, expressed as percentages of the corresponding populations, but that the over-all labor force increase shown by the census data is much smaller than that shown by the MRLF data. Thus, the net increase in the labor force was about 6.6 million between 1940 and 1950 on the basis of the decennial census data, or about 2.2 million below the MRLF increase of 8.8 million over the decade. ${ }^{8}$

Unpublished census checks of the labor force enumeration in the 1950 decennial census compared with the MRLF indicate that, despite the greater sampling variability of the latter survey, the higher labor force total in the MRLF is probably the more accurate. However, from the standpoint of analysis of trends

7 "Employment and Income in the United States, by Regions: 1950," 1950 Census of Population, Preliminary Reports, Series PC-7, No. 2, p. 1.

8 This comparison slightly understates the "true" increase, based upon decennial census data, since the preliminary census report for 1950 excludes from the labor force about 1.2 million persons 14 years and over whose employment status had not been reported. The corresponding census estimates for 1920-40 as shown in Table 3 have been adjusted by Durand to include a portion of the "not reported" group in the labor force. In 1940 about one-fourth of this group was estimated to be in the labor force. A corresponding adjustment for 1950 would have increased the decennial census labor force estimate by about 300,000 . 
THE LABOR FORCE

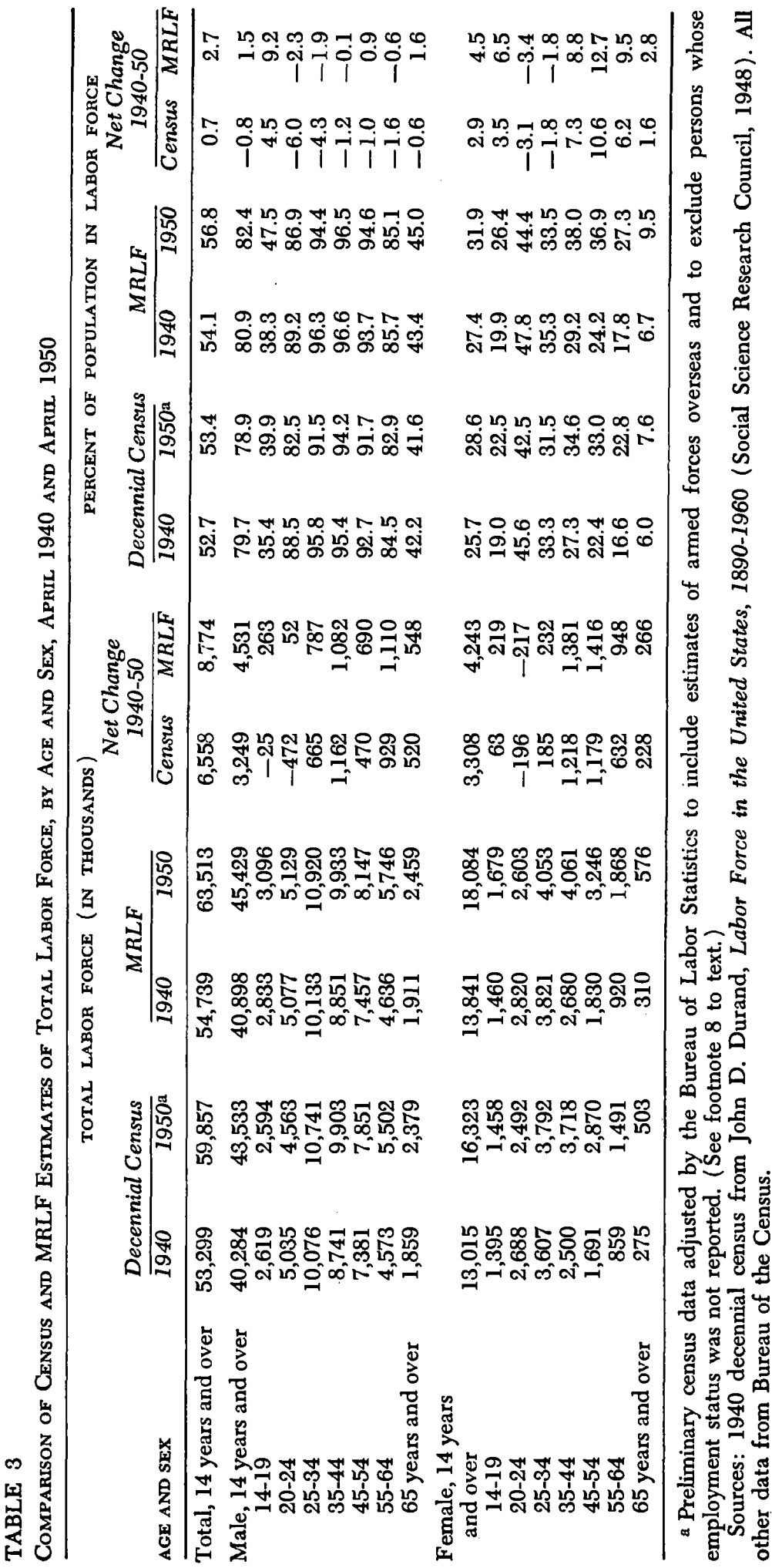


between 1940 and 1950, no definite conclusions can be drawn from the currently available data. It is likely that, to some extent, the greater labor force increases shown by the MRLF over the decade may reflect progressive improvements in enumeration techniques by the census sample survey staff. If this hypothesis is valid, it is possible that, for purposes of comparison with the decennial census data prior to 1940 (when similar limitations in training of enumerators existed), the 1940-50 decennial census changes may be the more consistent.

For purposes of the present paper, the preliminary 1950 decennial census results are used for comparison with earlier census data in analysis of past trends, while the level of the current MRLF series as of April 1950 is used as a base for projecting future trends.

\section{Factors affecting long-term trends}

The brief review of some of the problems of labor force measurement illustrates one of the basic limitations of any long-term labor force projection. Clearly, a projected labor force can be no more realistic than the past or current data upon which it is built. It is doubtful that censuses prior to 1940 were any more accurate than the more recent ones; they may well have been less so. In addition, the necessity of adjusting "gainful worker" data to levels comparable to the current labor force concept adds another element of uncertainty to the analysis of long-term trends. Detailed cross-classifications of labor force status by such pertinent characteristics as family status or school enrollment are also generally lacking in censuses prior to 1940. These factors, alone, are sufficient to proscribe any elaborate statistical manipulation of past census data, as a basis for extrapolation of future long. term trends.

Despite these limitations, the general direction of labor force trends for broad population groups, as reflected in the available data, has been fairly consistent over a period of decades, with some notable exceptions. Table 4 summarizes the labor force participation rates (or "worker rates") by sex and age groups since $1920 .^{\circ}$ The over-all ratio of labor force to population 14

${ }^{9}$ Data prior to that date are not shown because of major difficulties of comparability (particularly in the case of the 1910 data) and because the relevance of movements prior to World War I for coming decades is somewhat questionable. 
years and over has shown little net change since 1920, with the exception of the war period, but this has been a net effect of a complex of social and economic forces which have had contrasting effects on the work propensities of different population groups. Thus, the continued decline in the importance of agriculture in the economy and the accompanying movement from farm to city have tended to reduce the gainful activity of teen-age youth and of older men, but have expanded employment opportunities for women. Other major occupational shifts, such as the rising importance of the white-collar occupations and of semiskilled industrial jobs, have also operated in this direction.

TABLE 4

Percentage of Population in the Labor Force, by Age and Sex, 1920-50

\begin{tabular}{|c|c|c|c|c|c|c|c|}
\hline \multirow[b]{2}{*}{ AGE AND SEX } & \multicolumn{4}{|c|}{$\begin{array}{c}\text { COMPARABLE WITH } \\
\text { DECENNIAL CENSUS DATA }\end{array}$} & \multicolumn{3}{|c|}{$\begin{array}{c}\text { COMPARABLE } \\
\text { WITH MRLF DATA }\end{array}$} \\
\hline & 1920 & 1930 & 1940 & $1950^{\mathrm{a}}$ & 1940 & 1945 & 1950 \\
\hline $\begin{array}{l}\text { Total, } 14 \text { years } \\
\text { and over }\end{array}$ & 54.3 & 53.7 & 52.7 & 53.4 & 54.1 & 62.3 & 56.8 \\
\hline $\begin{array}{l}\text { Male, } 14 \text { years } \\
\text { and over } \\
14-19 \\
20-24 \\
25-34 \\
35-44 \\
45-54 \\
55-64 \\
65 \text { years } \\
\text { and over }\end{array}$ & $\begin{array}{l}84.5 \\
51.5 \\
89.9 \\
95.7 \\
95.4 \\
93.5 \\
86.3 \\
\\
55.6\end{array}$ & $\begin{array}{l}83.1 \\
40.1 \\
88.8 \\
96.0 \\
95.7 \\
93.8 \\
86.5\end{array}$ & $\begin{array}{l}79.7 \\
35.4 \\
88.5 \\
95.8 \\
95.4 \\
92.7 \\
84.5\end{array}$ & $\begin{array}{l}78.9 \\
39.9 \\
82.5 \\
91.5 \\
94.2 \\
91.7 \\
82.9\end{array}$ & $\begin{array}{l}80.9 \\
38.3 \\
89.2 \\
96.3 \\
96.6 \\
93.7 \\
85.7 \\
\\
43.4\end{array}$ & $\begin{array}{l}87.9 \\
67.2 \\
96.3 \\
96.6 \\
98.2 \\
97.4 \\
88.4\end{array}$ & $\begin{array}{l}82.4 \\
47.5 \\
86.9 \\
94.4 \\
96.5 \\
94.6 \\
85.1\end{array}$ \\
\hline $\begin{array}{l}\text { Female, } 14 \text { years } \\
\text { and over } \\
14-19 \\
20-24 \\
25-34 \\
35-44 \\
45-54 \\
55-64 \\
65 \text { years } \\
\text { and over }\end{array}$ & $\begin{array}{l}22.7 \\
28.3 \\
37.5 \\
23.7 \\
19.2 \\
17.9 \\
14.3\end{array}$ & $\begin{array}{l}23.6 \\
22.8 \\
41.8 \\
27.0 \\
21.7 \\
19.7 \\
15.3\end{array}$ & $\begin{array}{l}25.7 \\
19.0 \\
45.6 \\
33.3 \\
27.3 \\
22.4 \\
16.6\end{array}$ & $\begin{array}{l}28.6 \\
22.5 \\
42.5 \\
31.5 \\
34.6 \\
33.0 \\
22.8\end{array}$ & $\begin{array}{l}27.4 \\
19.9 \\
47.8 \\
35.3 \\
29.2 \\
24.2 \\
17.8\end{array}$ & $\begin{array}{l}37.0 \\
39.6 \\
55.6 \\
39.7 \\
41.6 \\
36.4 \\
27.4\end{array}$ & $\begin{array}{l}31.9 \\
26.4 \\
44.4 \\
33.5 \\
38.0 \\
36.9 \\
27.3\end{array}$ \\
\hline
\end{tabular}

Data refer to April, except the 1920 decennial census, which refers to January.

a Preliminary census data adjusted by the Bureau of Labor Statistics to include estimates of armed forces overseas and to exclude persons whose employment status was not reported. (See footnote 8 to text.)

Sources: Decennial census data: for 1920-40, John D. Durand, Labor Force in the United States, 1890-1960 (Social Science Research Council, 1948); for 1950, Bureau of the Census, Series PC-7, No. 2. 
In addition, there have been specific forces affecting the changing work propensities of the major population groups. In the case of youth, the extension of compulsory education and child labor laws intensified the effect of other basic socio-economic factors, such as urbanization and rising levels of family income. Similarly, in the case of older men, a long-term decline in relative employment opportunities has been accompanied by increased provision for social security and pension benefits.

For women, the rapid expansion of the white-collar fields and of lighter industrial jobs has been a major factor creating an increased demand for their services. At the same time, the prewar decline in the birth rate, the introduction of many laborsaving household appliances, and the shift of many functions from the household to the market economy have released an increasing proportion of women for work outside the home. The extent to which a change in any one of these factors can influence the over-all trends in labor force participation for the group is highlighted by the decline in worker rates among women aged 20-34 between 1940 and 1950, in contrast to the pronounced uptrend in earlier decades. This reversal is directly associated with the postwar upsurge in marriages and births: a much larger proportion of young women in the central child-bearing ages are currently fully occupied with the care of young children and are therefore not available for gainful employment. On the other hand, among older women past the child-bearing age, the uptrend in labor force activity has been particularly sharp, reflecting in part, perhaps, the relative shortage of younger women in the current labor market.

The relative influences of the various demographic, social, and economic factors upon historical trends in labor force participation have been the subject of intensive analyses by Wolfbein and Jaffe, Durand, Long, and others. Wolfbein and Jaffe, by standardizing changes in the over-all rates of labor force participation between 1890 and 1930 for the effects of specific demographic factors (i.e., age, sex, color, nativity, and marital status, for females), concluded that "social and economic forces are much more important than measurable demographic factors in accounting for changes in the proportion of the population in the labor force."10 Durand performed a detailed "factorial" analysis for

${ }^{10}$ S. L. Wolfbein and A. J. Jaffe, "Demographic Factors in Labor Force Growth," American Sociological Review, August 1946, p. 396. 
the period 1920-40, with additional allowance for the effects of changes in fertility among women and for urban-rural changes in residence. Partly because of his identification of urban-rural migration as a "demographic" factor, Durand has tended to give somewhat greater weight to the role of demographic changes, although recognizing the importance of socio-economic influence. ${ }^{11}$ Long, in his study of the labor force under changing conditions of employment and income, found an inverse relation between income and labor force participation among areas and individuals, but found no such correlation over time, and concluded that the over-all relationship of labor force to population was independent of the income level and remarkably constant.

Despite these intensive studies of factors affecting past labor force trends, the application of the findings to projections of the future labor force has been carried through to only a limited extent. For example, Durand has published a detailed projection of the labor force to 1960, based on projections of the population by age, sex, color, and marital and family status of women, but without correspondingly specific projections of the socio-economic factors affecting each of the separate population groups. It was necessary for Durand to assume that, for each population group, the net effects of these factors would tend to operate in about the same way in the future as in the past.

One possible danger in this assumption may be cited here. The contrast has been noted between the inverse correlation of income of family head with labor force participation of married women at a given time, on the one hand, and a positive correlation of rising income with rising labor force activity of married women over time, on the other. These observations are not, of course, necessarily contradictory. They merely serve to highlight the fact that, in a free economy, where a significant area of choice exists between working and other types of activity for certain population groups, visible changes in patterns of labor force participation are the net results of a whole complex of dynamic influences. It is quite conceivable that at some future date, the balance of these forces may be altered. In the case of married women, available data strongly indicate that the pull of expanding job opportunities, combined with a set of social values which has placed great emphasis on an expanding material standard of

11 John D. Durand, The Labor Force in the United States, 1890-1960 (Social Science Research Council, 1948), p. 67. 
living, has been a dominant factor in their steady flow into the labor force. There may be some theoretical rate of employment or level of real consumer income at which-under dynamic conditions-the benefits of further increments to family income will be offset by the disadvantages of less adequate household or child care, the loss of leisure, and the other real sacrifices resulting from the dual responsibilities of working women to their family and their job.

However, we need to know much more than we do about the basic relationships among these factors, under both static and dynamic conditions, in order to test a hypothesis of this type and incorporate it into a quantitative projection. Meanwhile, the analyst who is called upon for labor force projections today must still rely upon oversimplified extrapolations, reflecting the net effects of these various forces upon specific population groups, rather than attempt the much more complex task of forecasting their separate influences.

\section{Major assumptions}

In an extrapolation of this type, the major socio-economic assumptions are, in a sense, identified by the choice of base levels and of the method of estimating past trends. For purposes of projecting a peacetime "full-employment" labor force in 1975, the MRLF pattern of labor force participation by age and sex prevailing in April 1950 provided a convenient point of departure. The level of unemployment of 3.5 million, or 5.7 percent of the civilian labor force in April 1950, was somewhat greater than "frictional," but not sufficiently so to materially affect the over-all level of labor force participation as compared with the earlier postwar period of "full employment," in 1947-48.

One minor abnormality in the 1950 data from the standpoint of long-term projection was the temporary absence from the labor force of about 750,000 World War II veterans, mainly in the age group 20-34 years, who were attending schools under the G.I. Bill of Rights. Since nearly all of these veterans are expected to complete their training in the next few years, an allowance was made for this group in the 1950 worker rates for men aged 20-34 years, based upon a comparison of veteran and non-veteran worker rates in these age groups and upon related data on veterans' school enrollment trends.

Apart from this temporary factor, analysis of past labor force 
trends reveals no significant change in the worker rates for men in the age groups 25-54 years, apart from minor statistical aberrations. In these ages, nearly all men typically work or seek work except for a small percentage who, at any time, may be disabled, confined in institutions, or otherwise unavailable for work. The projected worker rates for these age groups were held constant at the adjusted April 1950 levels.

For all other age-sex groups, projections of worker rates were based on net rates of change between 1920 and 1950, with a special adjustment (for adult women) based on postwar trends between 1947 and 1950. (See Table 5.) The selection of the 1920-50 period was based on the following considerations:

1. Labor force data prior to 1920 were subject to larger relative errors of measurement and were too far removed from the operation of recent socio-economic forces.

2. Both 1920 and 1950 were years of relative prosperity, and followed-with somewhat varying time lags-a period of largescale mobilization. In these respects, they are more comparable than the intervening decennial years, 1930 and 1940.

3 . The time span of 30 years is sufficiently wide to reflect the operation of a number of major socio-economic trends: the continued relative decline of agriculture in the economy, the rapid growth of mass-production and other large-scale enterprise, the rising importance of the white-collar occupations, the establishment of social security and pension programs, etc. It was a period of rising productivity and of a general increase in the standard of living. It seems reasonable to assume that these broad trends will continue into the future, although probably at different rates.

4. Finally, the proportion of women with young children in 1920 more closely resembled that of the postwar period than did the proportion in either of the two intervening decennial years. ${ }^{12}$ The effects upon worker rates for women due to intervening movements of the marriage and birth rates have thus been minimized.

In projecting worker rates to 1975 , average annual rates of change between 1920 and 1950 were extrapolated to 1975 for those age-sex groups with declining trends in labor force participation, i.e., the 14- to 19-year olds, males aged 20-24 years, and

12 This is indicated by comparisons of the proportion of mothers of children under 10 years among native, white, married women in 1920, 1930, 1940, and 1946, appearing in Durand, op.cit., p. 231. 


\section{THE LABOR FORCE}

males 55 years and over. A relative, rather than an arithmetical, change in worker rates was applied, as the latter would have ultimately resulted in negative values. In the case of women in age groups 20 years and over, either an arithmetic or an exponential trend fitted to the rising pattern of worker rates would ultimately yield values over 100 percent. For these groups, the

TABLE 5

Pencentage of Population in the Labor Force, by Age and Sex, Actual (1950) and Projected (1975)a

\begin{tabular}{|c|c|c|c|}
\hline AGE AND SEX & $\begin{array}{c}\text { ACTUAL } \\
1950\end{array}$ & $\begin{array}{c}\text { P } \mathrm{O} \mathrm{J} \\
\text { Based on } \\
1920-50 \text { Trend }\end{array}$ & $\begin{array}{l}\text { T E } \mathrm{D}, 1975^{\mathrm{b}} \\
\text { Adjusted for } \\
\text { Postwar Changes }\end{array}$ \\
\hline Total, 14 years and over & 56.8 & 56.2 & 57.2 \\
\hline $\begin{array}{l}\text { Male, } 14 \text { years and over } \\
14-19 \\
20-24 \\
25-34 \\
35-44 \\
45-54 \\
55-64 \\
65 \text { years and over }\end{array}$ & $\begin{array}{l}82.4 \\
47.5 \\
86.9 \\
94.4 \\
96.5 \\
94.6 \\
85.1 \\
45.0\end{array}$ & $\begin{array}{l}78.8 \\
38.4 \\
83.7 \\
96.0 \\
96.5 \\
94.6 \\
82.3 \\
35.3\end{array}$ & $\begin{array}{l}78.8 \\
38.4 \\
83.7 \\
96.0 \\
96.5 \\
94.6 \\
82.3 \\
35.3\end{array}$ \\
\hline $\begin{array}{l}\text { Female, } 14 \text { years and over } \\
14-19 \\
20-24 \\
25-34 \\
35-44 \\
45-54 \\
55-64 \\
65 \text { years and over }\end{array}$ & $\begin{array}{r}31.9 \\
26.4 \\
44.4 \\
33.5 \\
38.0 \\
36.9 \\
27.3 \\
9.5\end{array}$ & $\begin{array}{r}35.1 \\
21.8 \\
48.1 \\
39.2 \\
48.0 \\
46.7 \\
33.4 \\
9.8\end{array}$ & $\begin{array}{l}37.1 \\
21.8 \\
48.6 \\
40.7 \\
49.0 \\
52.2 \\
35.4 \\
11.8\end{array}$ \\
\hline
\end{tabular}

a Comparable to current MRLF at April seasonal level.

b Percentages for group totals computed on basis of "medium" population projections.

average annual rate of decline between 1920 and 1950 in the proportion of women not in the labor force was projected to 1975. The worker rates were then derived as the complements of the projected "nonworker" rates in 1975.

For adult women aged 20 years and over, average annual rates of increase in labor force participation were significantly higher in the postwar period 1947-50 than in the longer period 1920-50. It is doubtful whether the recent rates of increase in labor force participation can be sustained for any long period. However, allowance was made for the continuation of the higher recent rate of increase for the equivalent of five years in the future, 
partly in recognition of possible lasting effects of the current defense program.

As in any other simple extrapolation of complex social variables, the extension of constant rates of change in worker rates for the coming 25 years is clearly subject to question. Over a sufficiently long period of time, this procedure would result in worker rates approaching zero for youth and older men, and in worker rates approaching unity for women-both of which extremes seem highly unreasonable at the present time. As more detailed information becomes available on factors affecting labor force participation, through analysis of the 1950 decennial census results and other sources, it may be possible to substitute more explicit assumptions and more refined methods for those described above. A range in projected labor force participation rates from "high" to "low" would also be desirable as a basis for constructing alternative economic models.

One approach toward projection of worker rates which may prove fruitful is through analysis of geographic differences for specific population groups. Preliminary analyses of this type, based on the 1940 decennial census and on sample census surveys of 34 metropolitan areas in April 1947, indicated that the relatively high projected worker rates for women in 1975 already prevailed in certain urban areas in the United States. Similarly, sharp geographic differentials in school enrollments support the possibility of a continued long-term decline in work activity among youth, simply as a result of a "catching-up" process in the more backward areas. The projected decline in labor force participation among older men, although consistent both with prewar and with recent postwar trends, is subject to a particularly wide margin of error. In an expanding economy and with a more highly trained and flexible labor force, it may be possible for a greater proportion of men than shown in the projection to remain in gainful employment until advanced ages.

\section{The 1975 labor force}

On the basis of the projected pattern of worker rates and of the "medium" and "high" projections of the population for 1975, projections of the labor force are shown in Table 6, by age and sex. These indicate that, in the next 25 years, the United States labor force will increase by between 23 and 31 million above the level prevailing in April 1950, or at an average annual rate of 


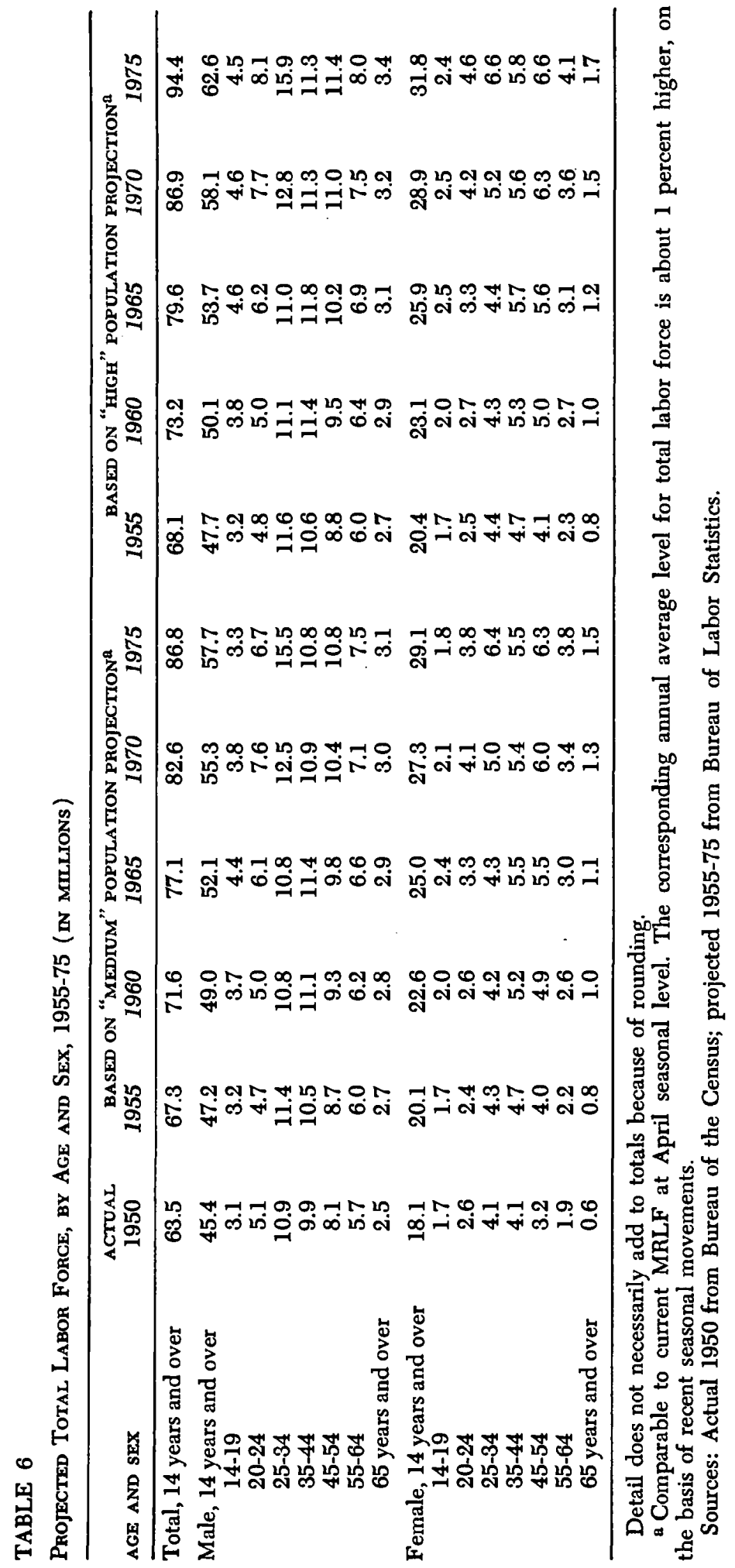


about 1 million per year. The projection is based on the fundamental assumptions of a continuation of past trends in labor force participation (as reflected in changes between 1920 and 1950 and in the recent postwar period) and of maintenance of an expanding economy with high levels of employment opportunity. It also presupposes that there will be no major war, or other disaster, which might substantially alter the previous work patterns of the population.

The rate of labor force growth may be expected to vary considerably over the next 25 years. On the basis of population trends and projected trends in worker rates, a smaller than average annual increase would be expected during the coming five years, when the relatively small population group born during the 1930's will be entering working age. A sharp rise in labor force growth is then indicated for the late 1950's and the decade of the 1960 's, resulting from the wartime and postwar baby booms. Thereafter, the rate of labor force growth will be dependent in large measure upon the trends of the birth rate during the current decade. For example, if births during the current decade are at the "medium" level, a pronounced decline in the rate of labor force growth will occur in the period 1970-75; however, if fertility is maintained at the projected "high" level, annual increments to the labor force in the early 1970 's may continue to rise.

Apart from population movements, annual changes in the size of the labor force will be significantly affected by cyclical movements in business activity, by changes in the international situation and in the level of munitions production (short of all-out war), and by a complex of other short-term factors. For example, the Bureau of Labor Statistics has projected a labor force increase of 3.2 million, or about 1.4 million greater than "normal," between late 1950 and late 1952, in response to the demands generated by the national defense program..$^{13}$ If the rate of defense production levels off or declines after 1952, this may be offset by smaller than normal increases in subsequent years.

It is noteworthy that the over-all ratios of labor force to the population 14 years and over, as projected for 1975, show very little net change from 1950. This would not necessarily hold true

13 Projected Manpower Requirements and Supply for the Defense Program, 1950-52, Manpower Report 7 (mineographed, Bureau of Labor Statistics). 
for the relationship of labor force to total population; the latter, however, has not been projected in view of the uncertainty as to future birth-rate trends. The empirical observation of a fairly stable peacetime relation of the labor force to population 14 years and over in recent decades and in our projection for 1975 does not by itself warrant any broad, theoretical generalization. It is the net result of a number of contrasting trends which have largely offset each other; i.e., declining rates for youth and older men, increasing rates for women, and changes in the age-sex structure of the population. There is no a priori reason to believe that these forces will have the same effect for an indefinite period in the future.

\section{Implications of labor force projections}

The projected labor force trends for the separate population groups have many implications for the working life pattern of the American population and for major issues of social and economic policy. Some of these are noted briefly below.

Women. Women will account for nearly half of the projected labor force growth between 1950 and 1975. The greatest relative increases for any age group will occur among women aged 35-54 years, of whom about half are expected to be in the labor force in 1975, as contrasted to a worker rate of less than two-fifths in 1950 and less than one-fifth in 1920. On the other hand, relatively small increases in work activity are projected for younger adult women in the age group 20-34 years, since under assumed prosperity conditions, marriage and birth rates are likely to remain high. This trend accentuates the U-shaped pattern of labor force participation of women over the life cycle, with an initial high rate in the late teens and early $20^{\circ}$ s, before most women marry and start families; a decline during the central child-bearing period of the late 20's and early 30's; and a return flow into gainful activity as children grow older and leave home, with a consequent reduction in household responsibilities. Planning for a "second working life" and for a longer average period of gainful activity will therefore become increasingly important in the education and counselling of women.

Youth. A declining trend in labor force activity is shown for teen-age youth of both sexes and for young men aged 20-24 years, reflecting a continued extension in the period of schooling. The projected reductions in worker rates are relatively moderate 
and do not fully reflect the assumed increase in school enrollment at the high school, college, and postgraduate levels. In recent years, about one-fourth of all students in the age group 14-19 years have also been in the labor force, mainly on a part-time basis. Under full-employment conditions, a continuation of a pattern of work outside of school hours (and particularly during vacation periods) may be expected and will limit the net decline in labor force participation for these age groups.

Older men. A slight decline of labor force participation among men 55 to 64 years of age and a larger decline (from 45 percent in 1950 to 35 percent in 1975) for men 65 years and over have been projected. If past trends are to be arrested, positive social and economic measures will have to be adopted by industry, labor, and government agencies, in order to avoid the economic wastage and individual frustrations resulting from premature separations of many older persons from gainful activity. 